\title{
Sensitive Estrogens Determination in Wastewater Samples by HPLC and Fluorescence Detection
}

\author{
Marcus Vinicius de Liz, ${ }^{a}$ Bianca do Amaral, ${ }^{b}$ Sandra Stets, ${ }^{b}$ Noemi Nagata ${ }^{b}$ and \\ Patricio Peralta-Zamora*,b \\ ${ }^{a}$ Departamento Acadêmico de Química e Biologia, Universidade Tecnológica Federal do Paraná, \\ 81280-340 Curitiba-PR, Brazil \\ ${ }^{b}$ Departamento de Química, Universidade Federal do Paraná, CP 19081, \\ 81531-980 Curitiba-PR, Brazil
}

\begin{abstract}
A sensitive high-performance liquid chromatography-fluorescence detection method (HPLC-FLD) was developed and validated for $17 \beta$-estradiol (E2) and $17 \alpha$-ethinylestradiol (EE2) determination in wastewater samples. Sample preparation was performed by solid-phase extraction (SPE) on Hypersep C18 cartridges. Conditioning and elution solvents and sample volume were investigated by a $2^{3}$ factorial design for both analytes. The pre-concentration factor was 2500 times, allowing to quantify $5.0 \mathrm{ng} \mathrm{L}^{-1}$ for both hormones. The SPE-HPLC-FLD method was successfully applied to detect and quantify trace amount of target compounds in raw and treated wastewater samples. E2 was found below limit of quantification in influent and effluent samples. Nevertheless, the recoveries of E2 in standard addition experiments were between 41 and $72 \%$, with relative standard deviations between 4 and 16\%. An important matrix effect was observed in the determination of EE2, with fluorescence signal suppression.
\end{abstract}

Keywords: estrogens, SPE, HPLC, fluorescence, wastewater

\section{Introduction}

Contamination of water resources represents a worldwide concern. Excessive population growth with the inefficient wastewater collection, particularly in developing countries, low treatment efficiency and inadequate sewage disposal, are the common causes of water contamination. ${ }^{1}$ Endocrine disrupting compounds (EDCs), especially estrogens, are chemical species that have negative activity on the endocrine system in humans $^{2,3}$ and animals. ${ }^{4,5}$

Estrone (E1), 17ß-estradiol (E2) and estriol (E3) are estrogens naturally produced by mammals and excreted mainly by pregnant and menstrual women via urine and feces. ${ }^{1}$ Otherwise, $17 \alpha$-ethinylestradiol (EE2) is a synthetic estrogen widely used as contraceptive and for therapeutic purposes such menopausal syndrome and prostate cancer control. ${ }^{6}$ Despite of being unregulated contaminants in environmental waters, they have already been included in the New Contaminant Candidate List-3 of the U.S.

*e-mail: zamora@ufpr.br
EPA and in the list of priority substances of the EU Water Framework Directive. ${ }^{7,8}$

These compounds have been detected in wastewater treatment plants (WWTP), ${ }^{9-12}$ in natural waters ${ }^{9,13}$ and, even in water supplies. ${ }^{14}$ Since 1990 , estrogenic activity has been detected in many countries. For instance, E1, E2, and EE2 were found in concentrations about $\mathrm{n} \mathrm{L}^{-1}$ in the effluent from a sewage treatment plant in the UK. ${ }^{15}$ In Brazil, monitoring studies of natural estrogens in domestic sewage also were initiated in the $90 \mathrm{~s} .{ }^{16}$ This study revealed estrogen concentrations between 20 and $40 \mathrm{ng} \mathrm{L}^{-1}$ and only partial removal by conventional treatments based on biological filter and activated sludge systems. Since then, other monitoring works reported the presence of endocrine disruptors in surface waters in Brazil. Sodré et al. ${ }^{17}$ detected E2 and EE2 between 38 to $2,510 \mathrm{ng} \mathrm{L}^{-1}$ and 6 to $310 \mathrm{ng} \mathrm{L}^{-1}$, respectively, in river water samples. Moreira et al. ${ }^{18}$ monitored river water samples for eight months and found EE2 and E2 in concentration levels between 5.6 to $63.8 \mathrm{ng} \mathrm{L}^{-1}$. The higher concentrations observed by Torres et al..$^{19}$ in surface and drinking water samples were $28,90,137$, and $194 \mathrm{ng} \mathrm{L}^{-1}$ to E1, E3, E2, and EE2, respectively. 
The estrogens monitoring in sewage and natural waters is a challenge due to the low concentration of the analytes and the complexity of the environmental matrices. Most of the reported methods to estrogens determination in aqueous samples involve preconcentration and clean-up processes such solid phase extraction (SPE), ${ }^{20-22}$ stir bar sorptive extraction (SBSE), ${ }^{23}$ solid-phase microextraction (SPME), ${ }^{24,25}$ and dispersive liquid-liquid microextraction (DLLME), ${ }^{26}$ among others. SPE followed by instrumental systems based on liquid chromatography, usually coupled with mass spectrometry detection, ${ }^{19,27,28}$ is the most employed procedure to detect estrogens in environmental samples. Despite that, these instruments are expensive and require high investment costs for their maintenance. ${ }^{29}$

High-performance liquid chromatography coupled with UV (HPLC-UV) $)^{30-32}$ and fluorescence detection (HPLC-FLD) $)^{26,29,33-35}$ have been reported as low-cost alternatives to HPLC-MS analysis, used to determine estrogens with quantification limits compatible with the concentration of estrogens in wastewater and natural waters. Lopes et al. ${ }^{36}$ showed the determination of E1 and E2 by SPE-HPLC-FLD in natural (600 ng $\mathrm{L}^{-1}$ of E1 in surface water, $6 \mathrm{ng} \mathrm{L}^{-1}$ of $\mathrm{E} 2$ in river spring) and treated waters (6.8 $\mathrm{ng} \mathrm{L}^{-1}$ of E2) in São Paulo (Brazil). Melo and Brito ${ }^{37}$ also developed an SPE-HPLC-FLD method and applied in the determination of EE2 in surface water and water supply of São Luis (Brazil), in which concentrations were below the limit of detection.

The aim of this study was the development of a high-performance liquid chromatographic method with fluorescence detection for the routine determination of $17 \beta$-estradiol (E2) and 17 $\alpha$-ethinylestradiol (EE2) in wastewater. The developed method was validated and employed in urban wastewater samples from the city of Curitiba (Paraná State, Brazil). To the best of our knowledge, no similar approach has been reported on developing a complete methodology and validation for simultaneous determination of estrogens in wastewater samples by SPE-HPLC-FLD in Brazil.

\section{Experimental}

\section{Materials}

All HPLC-grade solvents were purchased from J. T. Baker (Philipsburg, NJ, USA). 17 $\beta$-estradiol (E2, $\geq 98 \%$ ), estriol $(\mathrm{E} 3, \geq 97 \%)$ and $17 \alpha$-ethinylestradiol (EE2, $\geq 98 \%$ ), were purchased from Sigma-Aldrich (Steinheim, Germany). Individual standard stock solutions were prepared by dissolving an appropriate amount of standard in HPLC grade methanol and kept at $-4{ }^{\circ} \mathrm{C}\left(100 \mathrm{mg} \mathrm{L}^{-1}\right)$.
All aqueous solutions were prepared daily using ultrapure water (18.2 M $\Omega \mathrm{cm}$, Milli-Q system, Millipore, Bedford, MA, USA) from appropriate dilutions of the stock solution.

\section{Sampling and sample preparation}

Influent and effluent wastewater samples were collected from two anaerobic wastewater treatment plants located in Curitiba City, Paraná, Brazil. Typically, household wastewater is collected by underground sewage system and feed an upflow anaerobic sludge blanket (UASB) reactor. The post-treatment is performed by coagulation and flotation using ferric chloride $\left(\mathrm{FeCl}_{3}\right)$ or polyelectrolytes. Organic charge removal efficiency about $80 \%$ is obtained in these WWTP.

Sample volumes of 4 or $8 \mathrm{~L}$ were collected in amber bottle glass and stored at $4{ }^{\circ} \mathrm{C}$ until analysis. The maximum time of storage was 72 hours to minimize microbial degradation. Samples were filtered through a $0.6 \mathrm{~mm}$ filter (Macherey-Nagel, GF-3, Germany) in order to remove suspended solids.

Extraction of the selected compounds was performed with a PrepSep 20-port vacuum manifold (Waters, Milford, MA, USA) using Hypersep C18 cartridges ( $3 \mathrm{~mL}$ polypropylene tube, $500 \mathrm{mg}$, Thermo Scientific, USA). The SPE experimental conditions, such conditioning, elution solvents and sample volume were optimized by a full $2^{3}$ factorial design according to Table 1 . The cartridges were previously conditioned with $7 \mathrm{~mL}$ of acetonitrile, $5 \mathrm{~mL}$ of methanol and $5 \mathrm{~mL}$ of water according to the described in our previous paper ${ }^{38}$ and adapted from Girotto et al..$^{39}$ and López de Alda and Barceló. ${ }^{20}$ Briefly, extractions were performed at a flow rate of about $4 \mathrm{~mL} \mathrm{~min}^{-1}$. Afterward, the cartridges were drought with a gentle nitrogen flow and eluted with four aliquots of acetonitrile $(2.5 \mathrm{~mL})$. The eluate was concentrated to dryness with a gentle nitrogen flow and reconstituted with $0.150 \mathrm{~mL}$ of methanol, yielding an enrichment factor of 2,000 times. Final extracts were kept at $-4{ }^{\circ} \mathrm{C}$ until chromatographic determinations.

\section{Chromatographic determination}

High-performance liquid chromatography measurements were carried out on a Varian 920-LC chromatograph equipped with an autosampler, quaternary gradient pump and fluorescence detector (Agilent 1260). Routine chromatographic separations were performed on a C18 Microsorb column $(250 \times 4.6 \mathrm{~mm}, 5 \mu \mathrm{m})$ with a Metaguard pursuit C18 (4.6 mm i.d.) as guard column. The flow rate was $0.8 \mathrm{~mL} \mathrm{~min}^{-1}$ with an injection volume of $50 \mu \mathrm{L}$. The temperature was kept at $29^{\circ} \mathrm{C}$. Estrogens 
Table 1. SPE conditions to estrogens $\left(10 \mu \mathrm{g} \mathrm{L} \mathrm{L}^{-1}\right)$ evaluated in $2^{3}$ factorial design

\begin{tabular}{llcccc}
\hline \multicolumn{2}{c}{ Conditioning } & \multicolumn{2}{c}{ Sample volume $/ \mathrm{mL}$} & Elution \\
\hline$(-)^{\mathrm{a}}$ & \multicolumn{1}{c}{$(+)^{\mathrm{b}}$} & $(-)$ & $(+)$ & $(-)^{\mathrm{a}}$ & $(+)^{\mathrm{b}}$ \\
\hline $4 \mathrm{~mL}$ acetone & $7 \mathrm{~mL}$ acetonitrile & 100 & 500 & $2 \times 5 \mathrm{~mL}$ acetone & $2 \times 5 \mathrm{~mL}$ acetonitrile \\
$5 \mathrm{~mL}$ methanol & $5 \mathrm{~mL}$ methanol & & & & \\
$5 \mathrm{~mL}$ ultrapure water & $5 \mathrm{~mL}$ ultrapure water & & & \\
\hline
\end{tabular}

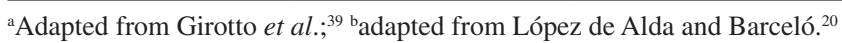

were determined by fluorescence detection at an excitation wavelength of $282 \mathrm{~nm}$ and an emission wavelength of $306 \mathrm{~nm}$. The analytes separation were achieved by gradient elution using water (A) and acetonitrile (B) as a mobile phase: A:B (90:10) was increased linearly to $42 \%$ of B in $70 \mathrm{~min}$ and then to $\mathrm{A}: \mathrm{B}(45: 55)$ in $10 \mathrm{~min}$. From 80 to 82 min, mobile phase B was increased linearly to $100 \%$ and this condition was held for $10 \mathrm{~min}$. Finally, the initial condition was returned in $2 \mathrm{~min}$ and held for $11 \mathrm{~min}$.

\section{Method validation}

The method developed was evaluated according to the following parameters: selectivity, linearity, detection and quantification limits, precision and accuracy. The linearity was tested in the concentration range studied: 2.0 to $200 \mu \mathrm{g} \mathrm{L}{ }^{-1}$ for E2 and EE2. The sensitivity for each hormone was evaluated by the average of three slope curves independently prepared. Selectivity was evaluated by comparing the analytes in the solvent (methanol) with wastewater samples fortified with $5.00 \mathrm{mg} \mathrm{L}^{-1}$. Extraction of $100 \mathrm{~mL}$ of aqueous solution at $20.0 \mu \mathrm{g} \mathrm{L}^{-1}$ of each estrogen prepared in different days was used to assess the precision (sextuplicate), expressed in relative standard deviation (RSD). The accuracy was determined by recovery at different concentrations of each estrogen. The limits of detection (LOD) and quantification (LOQ) were assessed according to visual evaluation for three analytical curves according guidelines from IUPAC ${ }^{40}$ and ICH. ${ }^{41}$ Robustness tests were performed on temperature and pressure of column variation.

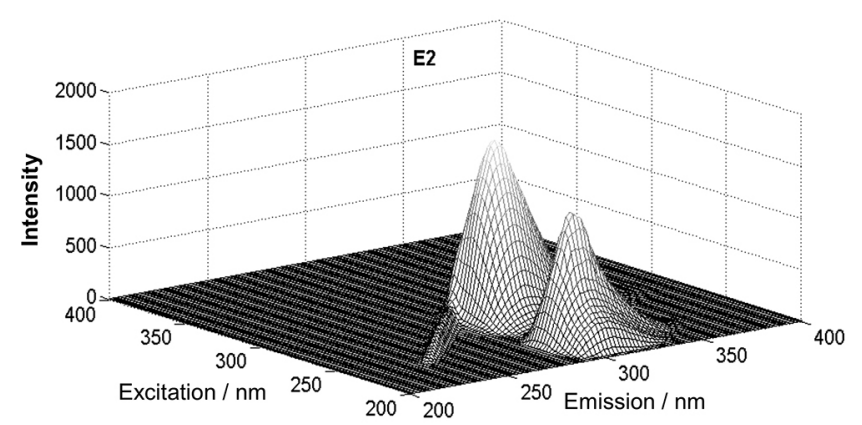

\section{Standard addition recovery studies}

Tree-hundred milliliters of wastewater were spiked with the hormones in triplicate at five concentration levels $\left(10,5075,100\right.$ and $\left.300 \mathrm{ng} \mathrm{L}^{-1}\right)$ and submitted to aging for 24 hours. Spiked samples were submitted to solid phase extraction described in Sampling and sample preparation section. The obtained chromatograms were confronted to the ones acquired from wastewater without standard addition, to the standard solutions and to samples with post-extraction fortification (approximately $0.6 \mathrm{mg} \mathrm{L}^{-1}$ ).

\section{Results and Discussion}

\section{Chromatographic method}

Figure 1 shows the fluorescence spectra of each hormone standards at $5 \mathrm{mg} \mathrm{L}^{-1}$ in aqueous solution. The natural fluorescence behavior is represented by a strong emission at $306 \mathrm{~nm}$ in 230 and $282 \mathrm{~nm}$ excitation wavelengths.

A detailed analysis of these spectral profiles shows there is a significant difference between the excitation wavelengths and high fluorescence intensities. Nevertheless, it is important to point out that most of the works have employed $230 \mathrm{~nm}$ as excitation wavelength ${ }^{29,33,37}$ which has a suitable response to river and drinking water samples. Nonetheless, wastewater samples showed high interference on fluorescence signal at $230 \mathrm{~nm}$ (Figure 2). Hence, $280 \mathrm{~nm}$ was selected as

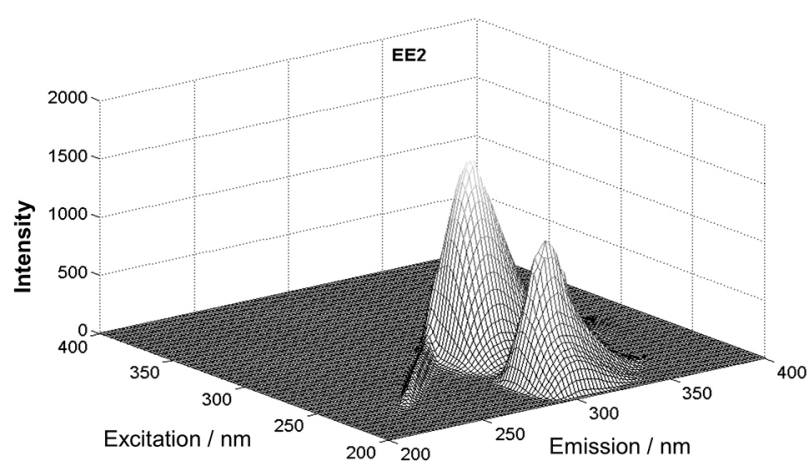

Figure 1. Excitation-emission fluorescence spectra of (a) $17 \beta$-estradiol and (b) $17 \alpha$-ethinylestradiol at $5 \mathrm{mg} \mathrm{L}^{-1}$. 
excitation wavelength to ensure suitable detectability of E2 and EE2 at trace level concentrations. Lima et al. ${ }^{26}$ and Kumar et al. ${ }^{34}$ also monitored estrogens in wastewater samples at $280 \mathrm{~nm}$ as excitation wavelength with minor matrix interference.

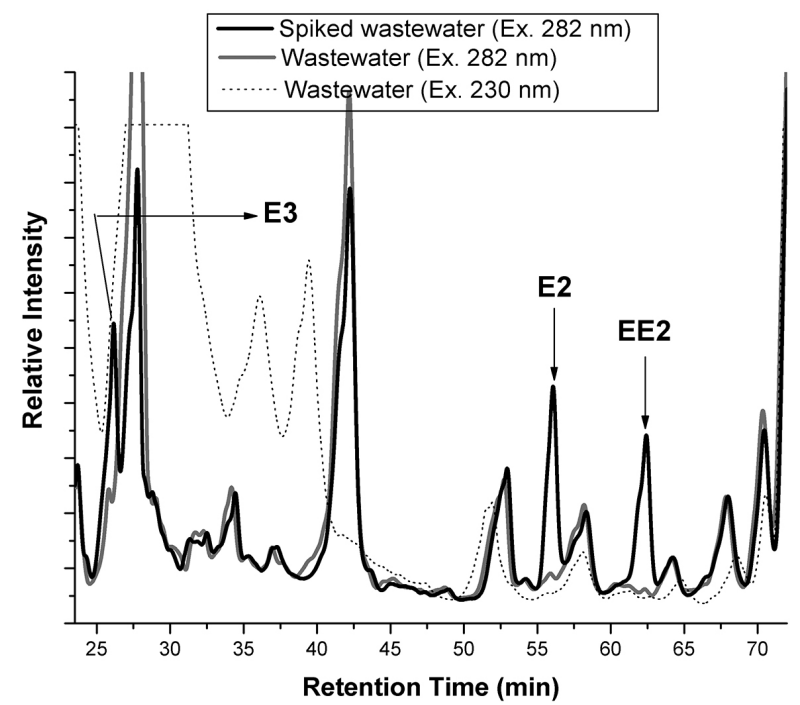

Figure 2. Typical chromatogram of natural and spiked wastewater samples (spiked at $600 \mu \mathrm{g} \mathrm{L}^{-1}$ ).

The chromatographic method was carefully developed in order to achieve a suitable resolution for both hormones. Thereby, different mobile phases with methanol, acetonitrile, and water were tested in several eluting programs. Acetonitrile was selected for further separations in the gradient elution program. Although the analytes separation could be achieved at a shorter elution time, the complexity of analyzed samples needed longer times to minimize matrix interference.

\section{Extraction procedure optimization}

The analysis of estrogens in aqueous matrices frequently involves samples volumes between 100 and $2000 \mathrm{~mL}$ and the use of preliminary procedures of filtration and extraction..$^{42}$ In the filtration process, the adsorption of estrogens on cellulose ester or nylon filters allowed losses between 30 and 50\%, respectively, of the analytes, which make it almost mandatory to use filters based on the glass fiber. $38,43,44$

Extraction processes are usually carried out by solid phase extraction, involving the use of cartridges containing silica $\mathrm{C} 18$ or polymeric sorbents and acetone, acetonitrile or methanol as the elution solvent. ${ }^{45} \mathrm{In}$ general, silica $\mathrm{C} 18$ cartridges have been widely used in estrogens extraction processes with two solvent systems: the first adopted acetone/methanol/water as conditioning solvent and acetone as elution solvent, while the second involves conditioning with acetonitrile/methanol/water and elution with acetonitrile. Therefore, in this study, the extraction efficiency of both procedures was evaluated by a factorial design using the average extraction recovery of the two studied estrogens (E2 and EE2) as processing response. Additionally, the effect of the sample volume was investigated, which configures a full $2^{3}$ factorial design.

Based on the estimated effects, and taking into account the typical deviation of triplicate analysis (approximately $6 \%$ ), it was observed that the extraction process was not significantly influenced by the studied variables. Although all procedures were very efficient, allowing recoveries between 85 and 95\%, slight recovery improvements were observed with acetonitrile in the conditioning and elution step as shown in Figure 3. Likewise, a slight improvement in the extraction capacity was observed for sample volumes of $500 \mathrm{~mL}$. This result is in accordance with those reported by López de Alda and Barceló, ${ }^{46}$ which suggest $500 \mathrm{~mL}$ as the operational limit for the SPE cartridges. The optimized extraction conditions were established as: mixture acetonitrile/methanol/water as conditioning solvent, acetonitrile as elution solvent and sample volume between 100 and $500 \mathrm{~mL}$, depending on the analysis requirements.

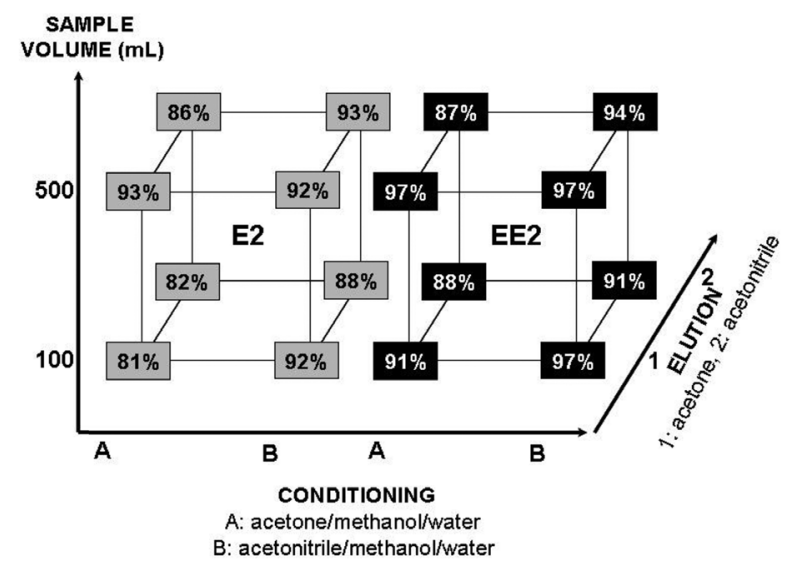

Figure 3. Geometrical representation of the $2^{3}$ factorial designs used to optimize the SPE of selected estrogens.

The recovery of estrogens from aqueous solution was also evaluated under different analytes concentration between 0.01 and $20.00 \mu \mathrm{g} \mathrm{L}^{-1}$, samples volumes between 100 and $500 \mathrm{~mL}$ and reconstitution volumes between 0.1 and $1.0 \mathrm{~mL}$. The results in Table 2 showed excellent recoveries for concentrations up to $10 \mathrm{ng} \mathrm{L}^{-1}$, which were obtained mainly due to the high sensibility of the fluorescence detector and the preconcentration factors of 2,000 to 2,500 times. This limit of quantification is lower than those reported by Sodré et al..$^{47}$ that implemented an extraction method and liquid chromatography-tandem 
Table 2. Recovery of estrogens from aqueous solution by SPE extraction under different preconcentration levels

\begin{tabular}{lcccc}
\hline \multirow{2}{*}{ Concentration $/\left(\mu \mathrm{g} \mathrm{L}^{-1}\right)$} & Sample volume $/ \mathrm{mL}$ & Final volume $/ \mathrm{mL}$ & \multicolumn{2}{c}{ Recovery \pm RSD $/ \%$} \\
\cline { 3 - 5 } 20.00 & 100 & 1.00 & $99.2 \pm 11.7$ & EE2 \\
10.00 & 100 & 1.00 & $98.0 \pm 2.0$ & $98.8 \pm 10.5$ \\
0.50 & 100 & 1.00 & $93.0 \pm 1.9$ & $97.0 \pm 5.6$ \\
0.50 & 200 & 1.00 & $96.6 \pm 2.5$ & $91.4 \pm 3.9$ \\
0.10 & 100 & 1.00 & $74.9 \pm 35.8$ & $95.6 \pm 2.3$ \\
0.10 & 200 & 1.00 & $91.7 \pm 6.6$ & $102 \pm 19.8$ \\
0.10 & 500 & 1.00 & $89.0 \pm 9.2$ & $107 \pm 3.0$ \\
0.01 & 200 & 0.10 & $86.5 \pm 20.2$ & $92.4 \pm 2.2$ \\
0.01 & 300 & 0.15 & $99.1 \pm 0.7$ & $78.6 \pm 36.6$ \\
0.01 & 500 & 0.20 & $98.4 \pm 7.8$ & $103 \pm 3.1$ \\
\hline
\end{tabular}

aRSD: relative standard deviation $(\mathrm{n}=3)$.

mass spectrometry detection with preconcentration factors of 5,000 times.

\section{Performance of the analytical method}

Under optimized conditions, validation procedure was performed by the linear range and linearity, determination coefficient $\left(\mathrm{R}^{2}\right)$, LOD and LOQ as summarized in Table 3. The SPE-HPLC-FLD showed a good linearity for hormones in the range of 10 to $200 \mu \mathrm{g} \mathrm{L}^{-1}$ for $\mathrm{E} 2$ and EE2 with determination coefficients higher than 0.99. The instrumental precision (HPLC-FLD method) was evaluated by determination of a sample containing $100 \mu \mathrm{g} \mathrm{L}^{-1}$ of each estrogen, in triplicate. The gradient elution utilized allowed relative standard deviation lower than $5 \%$.

The LOD and LOQ were calculated by visual evaluation which is a precision-based approach. Analytes concentration were systematically decreased and the value accepted as quantitation limit exhibited $20 \%$ as the maximum relative standard deviation. In this work $5.0 \mathrm{ng} \mathrm{L}^{-1}$ for both estrogens was found as LOQ. The value immediately below this concentration but with the standard deviation greater than $20 \%$ was considered the limit of detection $\left(2.5 \mathrm{ng} \mathrm{L}^{-1}\right)$. LOD and LOQ were also obtained by curve parameters method ( 0.835 and $2.54 \mathrm{ng} \mathrm{L}^{-1}$ for E2, respectively; 2.56 and $7.8 \mathrm{ng} \mathrm{L}^{-1}$ for EE2, respectively). Lower values for E2 and similar results for EE2 were obtained in both methods. Since the latter method is most applicable when the analysis has no significant background noise ${ }^{48}$ the first method was adopted in this work as shown in Table 3. It is important to point out that instrumental limits of quantification associated with preconcentration factors of 2000, allowed quantitation limits of $5 \mathrm{ng} \mathrm{L}^{-1}$ for E2 and EE2, which is consistent with the proposed study.
Table 3. Analytical method performance to estrogens determination in aqueous standard solutions

\begin{tabular}{lcc}
\hline & E2 & EE2 \\
\hline Equation & $\mathrm{Y}=-0.342+74.94 \mathrm{X}$ & $\mathrm{Y}=-0.244+66.59 \mathrm{X}$ \\
$\mathrm{R}^{2}$ & 0.9998 & 0.9955 \\
$\mathrm{LCR}^{\mathrm{a}} /\left(\mu \mathrm{g} \mathrm{L}^{-1}\right)$ & $10-200$ & $10-200$ \\
$\mathrm{n}$ & 10 & 10 \\
$\mathrm{LOD}^{\mathrm{b}} /\left(\mathrm{ng} \mathrm{L}^{-1}\right)$ & 2.5 & 2.5 \\
$\mathrm{LOQ}^{\mathrm{c}} /\left(\mathrm{ng} \mathrm{L}^{-1}\right)$ & 5 & 5 \\
Recovery $\pm \mathrm{RSD}^{\mathrm{d}} / \%$ & $99.1 \pm 0.7$ & $103 \pm 3.1$
\end{tabular}

${ }^{a}$ LCR: linear calibration range; ${ }^{b} \mathrm{LOD}$ : limit of detection; ${ }^{\mathrm{L}} \mathrm{LOQ}$ : limit of quantification; ${ }^{\mathrm{RSD}}$ : relative standard deviation $\left(\mathrm{n}=3 ; 10 \mathrm{ng} \mathrm{L}^{-1}\right)$.

The recoveries of the two estrogens reached values higher than $97 \%$, whereas the standard deviation values achieved were in the order of $10 \%$. Although there is no maximum value for the random errors obtained in an analysis, 80 to $120 \%$ is considered acceptable as recovery rate with relative standard deviation up to $20 \%$ for micropollutants determination..$^{40,49}$ This is acceptable since analyte recovery depends on the concentration range, matrix complexity and the number of steps involved in the process. Lopes et al..$^{36}$ achieved recovery levels for E2 in SPE-HPLC-FLD method between 96 and $128 \%$ in surface water and between 86 and $93 \%$ in treated water, with coefficients of variation between 3 and $24 \%$, working with $1 \mathrm{~L}$ of sample. Montagner and $\operatorname{Jardim}^{50}$ developed an SPE-HPLC-FLD method with E2 and EE2 recoveries from 65 to $74 \%$ for water sample containing $1.0 \mu \mathrm{g} \mathrm{L}{ }^{-1}$ with coefficients of variation below 5\% for both analytes. The results obtained in the present study are in accordance with those reported in literature. 
The robustness of the method was evaluated by varying instrument parameters such as column temperature and pressure. While temperature and pressure modifies retention times (differences up to 10\%), integrated area values remain essentially unchanged. Hence, these parameters must be careful monitored in order not to affect reproducibility.

\section{Analysis of wastewater samples}

As shown in Figure 2, the fluorescence signal of an extracted sewage sample was very complex, even when an extended gradient system was adopted. A typical chromatogram of a pre-concentrated sewage sample is shown in Figure 4.

In most cases, chromatographic profile suggests the presence of E2 and the absence of EE2. Hence, standard addition studies from spiked sewage samples were carried

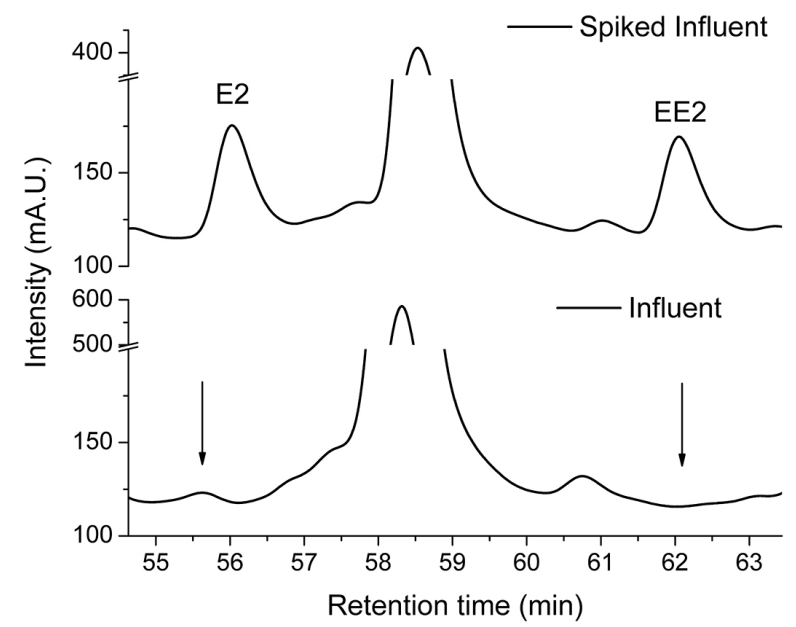

Figure 4. Detail of a typical fluorescence-based chromatogram of spiked and natural wastewater samples. out and the results showed recoveries between 40 and $70 \%$ (Table 4). This is a remarkable result, once few works reported estrogens recovery from complex samples such wastewater. The low recovery obtained may be attributed to signal suppression of the matrix components. According to results summarized by Gabet et al. ${ }^{51}$ the recovery of estrogens differs considerably with the type of matrix. For this reason, this parameter should be determined with real samples, an operation that could be extremely difficult due to the unavailability of non-contaminated matrices. Recently, Pailler et al. ${ }^{52}$ developed an LC-MS/MS method for quantification of micropollutants in natural waters including both hormones studied in this work. The author obtained recoveries between 92 and $110 \%$ for E2 and EE2, and a matrix effect with moderate signal suppression ranged from -3 to $-16 \%$ in relation to the signal registered for spiked deionized water. In most cases, matrix effects are the main challenge in quantitative analysis. ${ }^{19}$

In this work, EE2 was found below LOD in real samples. It was also observed an important matrix effect to EE2, with fluorescence signal suppression. However, the E2 concentration was determined directly by interpolation in analytical curves and by the standard addition system. The results shown in Table 4 are slightly different but have the same magnitude order. Considering the high sample complexity, standard addition method gave more realistic results, since matrix effects, which are a drawback of the HPLC-DAD (diode array detector) and HPLC-FLD methods, were corrected. The concentration of $\mathrm{E} 2$ is compatible with values reported in the recent literature, ${ }^{47,52}$ including some works that use chromatographic methods assisted by mass detectors. Instead the low recovery obtained, the estrogens were successfully determined in real samples.

Table 4. Recovery of E2 from wastewater samples (influent and effluent) using direct interpolation and standard addition methods

\begin{tabular}{|c|c|c|c|}
\hline Sample $(\mathrm{n}=3)$ & Concentration found / $\left(\mathrm{ng} \mathrm{L}^{-1}\right)$ & Recovery / \% & $\mathrm{RSD} / \%$ \\
\hline Influent $^{\mathrm{a}}$ & 5.96 & - & - \\
\hline Spiked influent (10 $\left.\mathrm{ng} \mathrm{L}^{-1}\right)$ & 7.16 & 71.7 & 4.06 \\
\hline Spiked influent (50 ng L $\left.{ }^{-1}\right)$ & 33.0 & 66.1 & 3.65 \\
\hline Spiked influent (75 ng L-1) & 47.8 & 63.8 & 11.4 \\
\hline Spiked influent (100 ng L-1) & 64.7 & 64.7 & 3.90 \\
\hline Influent $^{\mathrm{b}}$ & 3.39 & - & - \\
\hline Effluent $^{\mathrm{a}}$ & 2.98 & - & - \\
\hline Spiked effluent (10 ng L $\left.{ }^{-1}\right)$ & 4.08 & 40.8 & 13.1 \\
\hline Spiked effluent (50 $\left.\mathrm{ng} \mathrm{L}^{-1}\right)$ & 30.2 & 60.2 & 9.12 \\
\hline Spiked effluent $\left(75 \mathrm{ng} \mathrm{L}^{-1}\right)$ & 50.2 & 67.0 & 16.5 \\
\hline Spiked effluent (100 ng L $\left.{ }^{-1}\right)$ & 56.6 & 56.6 & 10.3 \\
\hline Effluent ${ }^{\mathrm{b}}$ & 0.61 & - & - \\
\hline
\end{tabular}

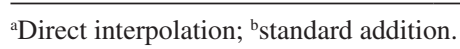


Table 5. Comparison of SPE-HPLC-FLD method developed with other methods for E2 and EE2 quantification in real samples

\begin{tabular}{|c|c|c|c|c|c|c|}
\hline Analyte & Matrix & Method & $\mathrm{LOD} /\left(\mathrm{ng} \mathrm{L}^{-1}\right)$ & Recovery / \% & Sample volume / mL & Reference \\
\hline E2, EE2 & wastewater & SPE-HPLC-FLD & 2.5 & $41-72$ & 300 & this study \\
\hline E2, EE2 & $\begin{array}{c}\text { tap water, surface water, and } \\
\text { wastewater }\end{array}$ & DLLME ${ }^{\mathrm{a}}$-HPLC-FLD & $2-6.5$ & $86-120$ & 8 & 26 \\
\hline EE2 & wastewater & in-tube-SPME ${ }^{\text {b }}$-HPLC-FLD & $5-10$ & $85.2-99.4$ & $0.075-0.10$ & 25 \\
\hline E2, EE2 & $\begin{array}{c}\text { drinking water, river water, } \\
\text { wastewater, and hospital } \\
\text { effluent }\end{array}$ & FPSE'-HPLC-FLD & $20-36$ & $89.0-98.0$ & 10 & 34 \\
\hline EE2 & drinking and river water & SPE-HPLC-FLD & 650 & 83 & 100 & 37 \\
\hline E2, EE2 & surface water and wastewater & SPE-LC-MS/MS & $0.2-1.0$ & 103-109 & 1000 & 47 \\
\hline
\end{tabular}

aDLLME: dispersive liquid-liquid microextraction; 'In-tube-SPME: in-tube solid phase microextraction; ${ }^{\mathrm{c}} \mathrm{FPSE}$ : fabric phase sorptive extraction.

Comparing other procedures based on high-performance liquid chromatography and fluorescence detectors (Table 5), quantification limits of the same order of magnitude of this work and similar recoveries around between 83 and 120\% were obtained for environmental samples.

\section{Conclusions}

A sensitive and accurate analytical method was developed for the simultaneous determination of estrogens in aqueous samples. The use of solid-phase extraction coupled with high-performance liquid chromatography with fluorescence detection achieved limits of quantification of $5.0 \mathrm{ng} \mathrm{L}^{-1}$ for E2 and EE2. The proposed method was applied to the determination of trace amount of estrogens in influents and effluents from a wastewater treatment plant. Unfortunately, the low concentration of the estrogens and the severe interference of the matrix fluorescence hindered the quantification of EE2 even at fortified levels. Neverthless, E2 could be detected in real samples below the limit of quantification. The recoveries to spiked samples were between 41 and $72 \%$, with relative standard deviations between 4 and $16 \%$.

\section{Acknowledgments}

Financial support from the National Counsel of Technological and Scientific Development (CNPq) and Araucária Foundation (PR, Brazil) is gratefully acknowledged. We also thank Coordination for the Improvement of Higher Education Personnel (CAPES) for the scholarships.

\section{References}

1. Barreiros, L.; Queiroz, J. F.; Magalhães, L. M.; Silva, A. M. T.; Segundo, M. A.; Microchem. J. 2016, 126, 243.
2. Schultz, M. M.; Minarik, T. A.; Martinovic-weigelt, D.; Curran, E. M.; Bartell, S. E.; Schoenfuss, H. L.; Environ. Int. 2013, 61, 138.

3. Treviño, L. S.; Wang, Q.; Walker, C. L.; Trevi, L. S.; Reprod. Toxicol. 2015, 54, 136.

4. Campbell, C. G.; Borglin, S. E.; Green, F. B.; Grayson, A.; Wozei, E.; Stringfellow, W. T.; Chemosphere 2006, 65, 1265.

5. Al-Ansari, A. M.; Saleem, A.; Kimpe, L. E.; Sherry, J. P.; McMaster, M. E.; Trudeau, V. L.; Blais, J. M.; Environ. Pollut. 2010, 158, 2566.

6. Reis Filho, R. W.; de Araújo, J. C.; Vieira, E. M.; Quim. Nova 2006, 29, 817.

7. USEPA CCL3, Water: Contaminant Candidate List 3; United States Environmental Protection Agency, 2009.

8. European Commission; European Community Directive 2000/60/EC of the European Parliament and of the Council of 23 October 2000 Establishing a Framework for Community Action in the Field of Water Policy; Official Journal of the European Union: Brussels, 2000, L327, 1.

9. Kuster, M.; López de Alda, M. J.; Hernando, M. D.; Petrovic, M.; Martín-Alonso, J.; Barceló, D.; J. Hydrol. 2008, 358, 112.

10. Pedrouzo, M.; Borrull, F.; Pocurull, E.; Marcé, R. M.; Water, Air, Soil Pollut. 2011, 217, 267.

11. Muz, M.; Sönmez, M. S.; Komesli, O. T.; Bakırdere, S.; Gökçay, C. F.; Analyst 2012, 137, 884.

12. Vymazal, J.; Březinová, T.; Koželuh, M.; Sci. Total Environ. $\mathbf{2 0 1 5}, 536,625$.

13. Martinovic-Weigelt, D.; Minarik, T. A.; Curran, E. M.; Marchuk, J. S.; Pazderka, M. J.; Smith, E. A.; Goldenstein, R. L.; Miresse, C. L.; Matlon, T. J.; Schultz, M. M.; Schoenfuss, H. L.; Environ. Int. 2013, 61, 127.

14. Nie, M.; Yang, Y.; Liu, M.; Yan, C.; Shi, H.; Dong, W.; Zhou, J. L.; Sci. Total Environ. 2014, 487, 785.

15. Desbrow, C.; Routledge, E. J.; Brighty, G. C.; Sumpter, J. P.; Waldock, M.; Environ. Sci. Technol. 1998, 32, 1549.

16. Stumpf, M.; Ternes, T. A.; Wilken, R.-D.; Rodrigues, S. V.; Aumann, W.; Sci. Total Environ. 1999, 225, 135. 
17. Sodré, F. F.; Montagner, C. C.; Locatelli, M. F.; Jardim, W. F.; J. Braz. Soc. Ecotoxicol. 2007, 2, 187.

18. Moreira, M.; Aquino, S.; Coutrim, M.; Silva, J.; Afonso, R.; Environ. Technol. 2011, 32, 1409.

19. Torres, N. H.; Aguiar, M. M.; Ferreira, L. F. R.; Américo, J. H. P.; Machado, Â. M.; Cavalcanti, E. B.; Tornisielo, V. L.; Environ. Monit. Assess. 2015, 187, 379.

20. López de Alda, M. J.; Barceló, D.; J. Chromatogr. A 2001, 938, 145.

21. Ciofi, L.; Fibbi, D.; Chiuminatto, U.; Coppini, E.; Checchini, L.; Del Bubba, M.; J. Chromatogr. A 2013, 1283, 53.

22. Chen, W.; Xue, M.; Xue, F.; Mu, X.; Xu, Z.; Meng, Z.; Zhu, G.; Shea, K. J.; Talanta 2015, 140, 68.

23. Silva, A. R. M.; Portugal, F. C. M.; Nogueira, J. M. F.; J. Chromatogr. A 2008, 1209, 10.

24. Ma, X.; Li, Q.; Yuan, D.; Talanta 2011, 85, 2212.

25. Aufartová, J.; Torres-Padrón, M. E.; Sosa-Ferrera, Z.; Solich, P.; Santana-Rodríguez, J. J.; Int. J. Environ. Anal. Chem. 2012, 92, 382.

26. Lima, D. L. D.; Silva, C. P.; Otero, M.; Esteves, V. I.; Talanta 2013, 115, 980 .

27. Guedes-Alonso, R.; Sosa-Ferrera, Z.; Santana-Rodríguez, J. J.; Santana-Rodríguez, J. J.; J. Anal. Methods Chem. 2013, 2013, 1.

28. Guo, F.; Liu, Q.; Qu, G.; Song, S.; Sun, J.; Shi, J.; Jiang, G.; J. Chromatogr. A 2013, 1281, 9.

29. Patrolecco, L.; Ademollo, N.; Grenni, P.; Tolomei, A.; Barra Caracciolo, A.; Capri, S.; Microchem. J. 2013, 107, 165.

30. Verbinnen, R. T.; Nunes, G. S.; Vieira, E. M.; Quim. Nova 2010 , 33, 1837.

31. Gañán, J.; Pérez-Quintanilla, D.; Morante-Zarcero, S.; Sierra, I.; J. Hazard. Mater. 2013, 260, 609.

32. Machado, K. S.; Cardoso, F. D.; Azevedo, J. C. R.; Braga, C. B.; Acta Sci. Technol. 2014, 36, 421.

33. Lisboa, N. S.; Fahning, C. S.; Cotrim, G.; dos Anjos, J. P.; de Andrade, J. B.; Hatje, V.; da Rocha, G. O.; Talanta 2013, 117, 168.

34. Kumar, R.; Gaurav; Heena; Malik, A. K.; Kabir, A.; Furton, K. G.; J. Chromatogr. A 2014, 1359, 16.
35. Kozłowska-Tylingo, K.; Konieczka, P.; Gustaw, E.; Wasik, A.; Namieśnik, J.; Anal. Lett. 2014, 47, 1449.

36. Lopes, L. G.; Marchi, M. R. R.; Souza, J. B. G.; Moura, J. A.; Lorenzon, C. S.; Cruz, C.; Amaral, L. A.; Quim. Nova 2010, 33, 639.

37. Melo, S. M.; Brito, N. M.; Water, Air, Soil Pollut. 2014, 225, 1783.

38. de Liz, M. V.; Nagata, N.; Peralta-Zamora, P.; Quim. Nova 2012, 35, 1213.

39. Girotto, G.; Nogueira, K. L.; Moura, J. A.; Souza, J. B.; Giacometti, L. L.; Marchi, M. R. R.; Tognolli, J. O.; Eclet. Quim. 2007, 32, 61.

40. Thompson, M.; Ellison, S. L. R.; Wood, R.; Pure Appl. Chem. 2002, 74, 835 .

41. ICH; ICH Harmonised Tripartite Guideline. Validation of Analytical Procedures: Text and Methodology Q2(R1); 2005.

42. Schäfer, A. I.; Akanyeti, I.; Semião, A. J. C.; Adv. Colloid Interface Sci. 2011, 164, 100.

43. Liu, M.; Lai, E. P. C.; Yang, Y.; Int. J. Recent Res. Appl. Stud. 2012, 11, 67.

44. Neale, P. A.; Pronk, W.; Shäfer, A. I.; Environ. Eng. Sci. 2009, $26,1157$.

45. Liska, I.; J. Chromatogr. A 2000, 885, 3.

46. López de Alda, M. J.; Barceló, D.; J. Chromatogr. A 2000, 892, 391.

47. Sodré, F. F.; Pescara, I. C.; Montagner, C. C.; Jardim, W. F.; Microchem. J. 2010, 96, 92.

48. Shrivastava, A.; Gupta, V.; Chron. Young Sci. 2011, 2, 21.

49. González, A. G.; Herrador, M. Á.; Asuero, A. G.; Talanta 2010, 82, 1995.

50. Montagner, C. C.; Jardim, W. F.; J. Braz. Chem. Soc. 2011, 22, 1452.

51. Gabet, V.; Miège, C.; Bados, P.; Coquery, M.; TrAC - Trends Anal. Chem. 2007, 26, 1113.

52. Pailler, J.-Y.; Krein, A.; Pfister, L.; Hoffmann, L.; Guignard, C.; Sci. Total Environ. 2009, 407, 4736.

Submitted: October 20, 2016

Published online: December 20, 2016 